\title{
REVELANDO A DIMENSÃo dA ÉTICA NO COTIDIANO DOS AGENTES COMUNITÁRIOS DE SAÚdE DE UM MUNICÍPIO DA REGIÃO NORTE DO ESTADO DO PARANÁ
}

\author{
Revealing the extent of ethics in the daily life of \\ community health workers in a city in the northof \\ the state of Paraná
}

Marcelo Marques Ferreira ${ }^{1}$, Cibele Isaac Saad Rodrigues ${ }^{2}$

\begin{abstract}
1. Marcelo Marques Ferreira, Secretário Municipal de Saúde de Rolândia e Mestre Profissional em Educação nas Profissões de Saúde - PUC-SP. ORCID: https://orcid.org/0000-0002-7353-4236

2. Cibele Isaac Saad Rodrigues, Professora Titular, Departamento de Medicina da Faculdade de Ciências Médicas e da Saúde da Pontifícia Universidade Católica de São Paulo. Professora de Bioética no Programa de Mestrado Profissional em Educação nas Profissões de Saúde.ORCID: https://orcid.org/0000-00019490-7997
\end{abstract}

CONTATO: Cibele Isaac Saad Rodrigues | Praça Dr. José Ermírio de Moraes, 290 | Jd. Vergueiro | Sorocaba | São Paulo | Brasil | CEP 18030-095 | E-mail: cibele.sr@gmail.com; cisaad@pucsp.br

COMO CITAR: Ferreira MM, Rodrigues CIS. Revelando a dimensão da ética no cotidiano dos agentes comunitários de saúde de um município da região norte do estado do Paraná. R. Saúde Públ. 2018 Dez;1(2):101-109.

(c) (i) COPYRIGHT Esta obra é disponibilizada nos termos da Licença Creative Commons - 4. 0

Internacional. É permitida a reprodução parcial ou total desta obra, desde que citada a fonte.

RESUMO Os Agentes Comunitários de Saúde (ACS) revelam-se atores intrigantes no diálogo entre saberes e práticas populares com o conhecimento científico. Não possuem Código de Ética Profissional que os respaldem ou são capacitados para solucionar questões éticas cotidianas. O objetivo deste trabalho foi revelar a percepção dos aspectos éticos inerentes ao trabalho dos ACS que atuam na Estratégia de Saúde da Família (ESF) em Rolândia (Paraná). Trata-se de estudo quantitativo e qualitativo, de ética descritiva. Participaram 52 mulheres, que atuam nas 12 equipes da ESF. Obteve-se perfil sociodemográfico, seguido de entrevista, onde as ACS foram expostas a três situações comuns em sua vivência. Utilizou-se "análise de conteúdo" para avaliação dos discursos. As participantes responderam satisfatoriamente considerando preceitos morais e declararam fundamental a existência de legislação 
deontológica específica. As entrevistas revelaram dilemas éticos profundos, fruto deste relacionamento próximo com a comunidade. Processo de intervenção educativa contextualizado foi proposto e aplicado às ACS.

RESUMO Agentes Comunitários de Saúde/ética. Bioética. Atenção Primária à Saúde. Saúde da Família/ ética.

ABSTRACT The Community Health Workers (ACS) prove to be intriguing actors in what concerns the dialogue between the common knowledge and practice and the scientific knowledge. They do not have a Code of Professional Ethics to endorse them, nor are they trained to solve ethical problems related to their daily life. The goal of this study was to reveal the perception of the inherently ethical aspects of ACSs who work in the Family Health Teams (ESF) in the city of Rolândia, Paraná, Brazil. The study was both quantitative and qualitative, and of descriptive ethics. The subjects were 52 female ACSs who work in the twelve teams of ESF. A social and demographic profile was obtained, followed by an interview, in which all ACSs were exposed to three situations that are common in their daily practice. The interviews were analyzed by the "content analysis" method. The participants' answers are, most of the time, correct and guided by their own moral principles. They all declared that the existence of specific deontological legislation is crucial. The interviews revealed deep ethical dilemmas that stem from this close relation to the community. A contextualized process of educational intervention was proposed and applied to the ACSs.

KEYWORDS: Community Health Agent. Professional Ethics. Bioethics. Family Health.

\section{INTRODUÇÃO}

$\mathbf{A}$

história da Estratégia Saúde da Família (ESF) está ligada à implantação de equipes multiprofissionais nas unidades básicas de saúde (UBS). Para o Ministério da Saúde (MS), a ESF é uma estratégia que visa atender ao indivíduo e à família de forma integral e contínua, desenvolvendo ações de promoção, proteção e recuperação da saúde. Tem como objetivo reorganizar a prática assistencial, centrada no hospital, passando a enfocar a família em seu ambiente físico e social'.

Participam destas equipes, no mínimo, um médico da família, um dentista, um enfermeiro, um auxiliar ou técnico de enfermagem e agentes comunitários de saúde (ACS). Estes profissionais atuam naquilo que se constitui a porta de entrada para o sistema, atentando para a continuidade e organização do cuidado de forma integral, valorizando a cultura local e obtendo os adequados registros de suas ações ${ }^{2}$.

O ACS tem-se revelado o ator mais intrigante no que se refere à relação de trocas estabelecidas entre saberes populares de saúde e saberes médico-científicos. É um ser humano que veicula as contradições e, simultaneamente, a possibilidade de um diálogo profundo entre esses dois saberes e práticas 3 .

Importante ressaltar que o ACS que trabalha na ESF tem maior proximidade com o usuário, por habitar o mesmo bairro e, ainda, por adentrar 
frequentemente o domicílio do usuário. Assim, consegue estabelecer novas relações no tocante às informações pessoais sobre a saúde individual e familiar, garantindo a privacidade daqueles com quem se relaciona na comunidade 4 .

Além disso, o ACS, por sua efetivação e configuração no trabalho com a comunidade e com os profissionais de saúde dentro da ESF e fora dela, lida com uma prática ética, humana e vinculada ao exercício da cidadania. Nesse sentido, os ACS são submetidos a situações em que são necessários conhecimentos de ética e bioética para o enfrentamento de tomada de decisões, no entanto não são capacitados formalmente e tampouco podem se apoiar em um código de ética profissional que os respalde, à semelhança das demais profissões da área da saúde.

Estudo realizado no município de Sorocaba (SP), no ano de 2011, ressaltou que, apesar do Programa dos Agentes Comunitários de Saúde (PACS) ter sido implantado no Brasil em 1991, a profissão de ACS somente foi reconhecida e regulamentada em 2002 pela Lei n 10.507. No entanto, algumas informações ficaram sem esclarecimentos precisos, como, por exemplo, a qual Conselho de Classe esse profissional estaria vinculado ${ }^{5}$.

Embora o conceito de ética profissional seja mais conciso, podemos nos deparar com situações em que a mesma conduta pode ser permitida no âmbito de uma determinada profissão e condenado no âmbito de outra. Assim, estabelecer um código deontológico para o profissional ACS pode constituir-se em referencial de conduta deste, nas relações com os demais profissionais da saúde, e também com os usuários do Sistema Único de Saúde (SUS).

Segundo a Associação Brasileira de Comunicação (ABRACOM): "a maior parte dos Códigos de Ética que conhecemos é o de moral, onde a moral é exatamente o conjunto de normas, regras, leis que orienta a vida dos individuos e grupos na sociedade, configurando o que se chama de "ethos", que é a marca da sociedade, o jeito de viver e relacionar-se, baseado em determinados valores". ${ }^{6}$

É no âmbito da ética que habitam os princípios normativos que devem estear as regras e as leis. Daí emerge o significado de se construir um Código de Ética, no qual se apresentam tais princípios norteadores das ações da organização, que se fazem válidos, não exclusivamente no âmbito interno, mas igualmente no contexto global da sociedade ${ }^{6}$.

Assim, o código de ética profissional tem por objetivo dirigir e fiscalizar o exercício da respectiva profissão, estabelecendo normas de conduta que o profissional deva observar no desempenho de suas atividades e suas relações com seus clientes e todas as demais pessoas com quem venha a ter contato.

Por esses motivos norteia esta pesquisa a pergunta: os ACS são capazes de identificar situações éticas em sua prática profissional cotidiana? Além disso, se ao identificá-las, conseguem desenvolver estratégias para solucioná-las?É neste sentido que esta pesquisa pretende contribuir para responder a indagações emergidas da prática profissional do pesquisador, auxiliando-o na busca de soluções em local onde atuava à época da coleta de dados como membro de uma das equipes de ESF.

Os objetivos foram: identificar a percepção dos aspectos éticos inerentes ao processo de trabalho dos ACS que atuam na ESF do município de Rolândia, localizado no norte do estado do Paraná; traçar o perfil sociodemográfico e de atividades desempenhadas por estes profissionais: revelar, por meio de depoimentos, o agir reflexivo e ético destes profissionais frente a situações éticas concretas e apontar estratégias educativas que potencializem o atuar ético dos ACS de Rolândia.

Adicionalmente, a pesquisa mostrou-se instrumento para a gestão municipal, pois ACS e gestores poderiam conhecer profundamente o cotidiano da prática profissional, na ausência de um código profissional de classe. 


\section{METODOLOGIA}

Trata-se de estudo, qualitativo e quantitativo, de ética descritiva, portanto, de cunho não normativo. O significado de ética descritiva compreende a verificação da conduta moral utilizando técnicas e metodologias de caráter científico visando conhecer como as pessoas equacionam e agem. Trata-se, portanto, de tarefa eminentemente científica e não de natureza filosófica7. Nesta direção identificamos a forma como os ACS atuam no cenário da prática profissional, entendendo a percepção de como estes profissionais raciocinam e agem.

O estudo foi desenvolvido no município de Rolândia, que integra a região Metropolitana de Londrina e está sob a jurisdição da $17^{a}$ Regional da Secretaria de Estado da Saúde, Macrorregião Norte do Paraná. Está situado no terceiro planalto do Norte do Paraná, com população estimada no ano de 2009 de 55.750 habitantes $^{8}$. Na ocasião da pesquisa, Rolândia contava com 72 (setenta e dois) ACS e a população de estudo foi constituída por 52 (cinquenta e dois).

As fontes de coleta de dados foram primárias, obtidas por entrevistas semiestruturadas com os ACS, utilizando-se questionários aplicados por alunas devidamente treinadas, matriculadas na última série do curso de enfermagem do Centro Universitário Filadélfia de Londrina.

As entrevistas semiestruturadas ocorreram durante a semana de 02 a 05 de julho de 2012, em horário alternativo compreendido entre 08h00min às 10h00min, ou seja, sem interferir nas atividades da equipe da ESF.

Primeiramente, um questionário foi aplicado às ACS para coleta dos dados sobre seus perfis sociodemográficos. Em um segundo momento, as alunas solicitaram que os entrevistados listassem problemas éticos a partir de uma narrativa de três casos hipotéticos, construídos pelos pesquisadores. As três situações éticas escolhidas foram: uma envolvendo um paciente hipertenso, uma com portador de Vírus da Imunodeficiência Humana (HIV) e uma com adolescente (QUADRO 1). Obviamente, tratam-se de situações já estabelecidas nas atribuições básicas dos ACS fundadas na Portaria GM/MS nº 1.886 de 18 de dezembro de $1997^{9}$.

Quadro 1. Situações Hipotéticas apresentadas ao ACS.

CASO 1- PERTURBANDO A ROTINA: a Senhora $\mathrm{J}$, hipertensa e diabética, frequentemente faz demandas que dificultam as atividades e perturbam a rotina da unidade de saúde. $\mathrm{O}$ agente de saúde da equipe na qual ela é cadastrada tenta acompanhála através da ficha de visita (ficha B) da melhor maneira possivel, mas a cada dia sente-se mais tentado a deixar de investir seus esforços visto que a paciente não quer a visita de nenhum agente comunitário de saúde.

CASO 2- PRESERVANDO A CONFIDENCIALIDADE: A senhora $\mathrm{M}$ tem HIV, e ela não quer contar para o marido sobre a doença. Pede para o agente de saúde sigilo sobre isso. A paciente relata ao agente de saúde que deseja que o marido faça o exame sem ele saber do que se trata.

CASO 3- ATENDENDO ADOLESCENTES: B, 12 anos de idade, procura o agente comunitário de saúde na qual está cadastrada e conta que está apaixonada por um rapaz. Seus pais acham que ela é muito jovem e a proíbem de namorar. A jovem diz que quer ter relações sexuais com o namorado. e pede para o agente de saúde orientá-la sobre preservativos. Pede ainda, ao agente de saúde, para não contar nada aos seus pais.

Fonte: Elaborado pelos autores (2012)

Os dados sociodemográficos foram analisados por meio do número absoluto de cada parâmetro, bem como de sua respectiva porcentagem em relação ao total dos ACS.

As entrevistas éticas propriamente ditas foram gravadas pelas alunas e depois analisadas pelo pesquisador através da metodologia da análise de conteúdo de Bardin. A análise de conteúdo objetiva entender as comunicações, de forma sistemática e científica, com objetivo de revelar o conteúdo das mensagens ${ }^{10}$. Por se tratar de estudo descritivo, os depoimentos dos ACS gravados foram transcritos na integra para que fosse dado tratamento descritivo, ou seja, foi feita a análise de seu conteúdo, por meio da organização do material obtido, seguida 
de codificação, classificação e categorização, sendo que esta última possibilitou a simplificação dos dados, facilitando sua interpretação.

O projeto de pesquisa foi analisado pelo Comitê de Ética em Pesquisa da Faculdade de Ciências Médicas e da Saúde da Pontifícia Universidade Católica de São Paulo, campus Sorocaba e, somente após sua aprovação, em 12 de junho de 2012 foi iniciada a coleta de dados.

\section{RESULTADOS}

A análise do perfil sociodemográfico mostrou que participaram da pesquisa 52 ACS, de um total de 72 possíveis, correspondendo a $73 \%$. A população de estudo foi de mulheres ( $n=52,100 \%)$, na faixa etária entre 20 e 40 anos ( $n=27,52 \%$ ), brancas ( $n=35,67 \%)$, casadas e com filhos $(n=38$, 73\%). A maioria cursou ensino médio completo $(n=$ $45,87 \%)$ e pratica a religião católica $(n=32,62 \%)$ além de atuar na ESF acima de 3 anos ( $n=43,82 \%)$ e apenas 18\% ( $n=9)$ trabalham há menos de dois anos. Todas residem na comunidade onde atuam, sendo que $86 \%(n=44)$ lá habitam há mais de 5 anos.

Os resultados podem ser resumidos na Tabela 1 quanto ao posicionamento dos ACS em relação às situações hipotéticas envolvendo conflitos éticos vivenciados na prática profissional.

Tabela 1. Posicionamento dos ACS em relação às situações hipotéticas envolvendo conflitos éticos vivenciados na prática profissional.

\begin{tabular}{|c|c|c|}
\hline QUESTÕES & $\begin{array}{l}\text { RESPOSTA } \\
\text { CERTA } \\
\text { № } \\
\%\end{array}$ & $\begin{array}{l}\text { RESPOSTA } \\
\text { INCORRETA } \\
\text { № } \\
\%\end{array}$ \\
\hline $\begin{array}{l}\text { No caso } 1 \text { - A - Se o ACS revela a outros ACS da equipe que a paciente é } \\
\text { hipertensa e grosseira, e relata que não quer acompanhá-la. Você acredita } \\
\text { que o ACS agiu certo ou errado? }\end{array}$ & $\begin{array}{c}42 \\
80 \%\end{array}$ & $\begin{array}{c}10 \\
20 \%\end{array}$ \\
\hline $\begin{array}{c}\text { Ainda no Caso } 1 \text { - B - Caso acredite que o ACS agiu errado } \\
\text { Ele deve ser punido? }\end{array}$ & $\begin{array}{c}30 \\
58 \%\end{array}$ & $\begin{array}{c}22 \\
42 \%\end{array}$ \\
\hline $\begin{array}{l}\text { No caso 2, se o ACS revelar o diagnóstico da doença ao marido da paciente, } \\
\text { ele cometeu uma falta de ética? }\end{array}$ & $\begin{array}{c}52 \\
100 \%\end{array}$ & $\begin{array}{c}0 \\
0 \%\end{array}$ \\
\hline $\begin{array}{l}\text { No caso } 3 \text { - A - Se o ACS não concordar com a adolescente por ela estar } \\
\text { tendo relações sexuais muito cedo, ele está cometendo falta de ética? }\end{array}$ & $\begin{array}{c}21 \\
40 \%\end{array}$ & $\begin{array}{c}31 \\
60 \%\end{array}$ \\
\hline Ainda no Caso 3 - B - Você ACS orientaria sobre o uso de Preservativos? & $\begin{array}{c}52 \\
100 \%\end{array}$ & $\begin{array}{c}0 \\
0 \%\end{array}$ \\
\hline
\end{tabular}

Fonte: Elaborado pelos autores (2012)

Em relação às duas questões (1A e 1B) arguidas na entrevista estruturada que expuseram conflitos éticos quanto ao sigilo, os resultados demonstraram uma média de acertos naquilo considerado eticamente certo de $80 \%(n=42)$ de acertos no Caso 1A e, no Caso 1B, 58\% de acertos $(n=30)$.
No caso 2 todos os ACS ( $n=52)$ tiveram 100\% de acerto quanto ao sigilo de informações, enquanto no caso 3 tivemos como resultados discordantes, sendo que no Caso 3 - A foram apenas $(n=21$, $40 \%)$ de acertos e no caso 3 - B ( $n=52,100 \%)$ de acertos.

No caso 1, (n=29,56\%) dos ACS já tiveram uma 
experiência na prática profissional, ou seja, mais da metade dos ACS vivenciaram o conflito ético expresso nesta situação. Importante afirmar que todos os ACS relataram trabalhar com pacientes do grupo de risco "hipertensos", ou seja, teoricamente deveriam saber lidar com as situações conflituosas provenientes deste atendimento, além de terem um documento padronizado denominado "Ficha B" como instrumento de acompanhamento que os norteia.

No caso 2, 52\% (n=27) dos ACS não vivenciaram ainda a situação posta com pacientes portadores do vírus HIV, destacando-se que estes eram os que têm menos tempo de carreira de trabalho no município, ou seja, ACS que trabalham entre um mês a dois anos. Já no caso 3, apesar de frequente na prática de um ACS, tivemos como resultado que apenas $(n=25,48 \%)$ dos ACS reconheceram essa experiência no cotidiano.

"Tivemos como resultado que 85\% ( $n=44)$ dos ACS sabiam da inexistência de um Código de Ética Profissional específico para o ACS e apenas 15\% ( $n=8)$ não tinham este conhecimento". Os ACS que afirmaram não saber se existe ou não um Código de Conduta ( $n=8,15 \%)$ tem curiosamente como experiência profissional entre um mês e dois anos de trabalho. Na realidade, chama a atenção o resultado que $100 \%$ dos ACS ( $n=52$ ) acham importante a elaboração de um Código deontológico norteador de suas ações, visto que outros profissionais da área da saúde como médico, enfermeiro, nutricionista e odontologista já o têm.

\section{DISCUSSÃo}

Após leitura exaustiva das respostas referentes ao Caso 1 notamos algumas impressões descritas pelos pesquisados que emergiram e foram classificadas nos seguintes grupos temáticos. A hipertensão arterial (HA) é uma síndrome de origem multifatorial, sendo um dos maiores problemas na área de saúde pública e tem sido reconhecida como grave fator de risco para as doenças cardiovasculares. Ressalta-se, ainda, o alto custo social em nosso meio, pois a HA é responsável por cerca de $40 \%$ dos casos de aposentadoria precoce e absenteísmo ao trabalho"11.

Os ACS foram numerados de 1a 52, objetivando análise dos resultados, mas respeitando o sigilo de suas identidades. Relataram por meio de seus depoimentos a realidade de acompanhamento do paciente crônico, qual seja a dificuldade de adesão às recomendações efetuadas. Os depoimentos descritos nesse eixo são somente os referentes aos ACS que relataram este fato durante a entrevista, já aqueles que não se ativeram a este aspecto ou responderam laconicamente "sim, já tive um caso", ou "não tive um caso assim" não foram descritos. É importante afirmar que $21 \%$ dos ACS relataram o depoimento durante a entrevista que serviram de fundamento do eixo deste estudo de caso que foram exemplificados durante a discussão geral, conforme classificação:

\section{Depoimento da ACS 1}

“(...) há pessoa que queria que eu visitasse, mas não acompanhasse (...)".

\section{Depoimento da ACS 9}

“(..) a gente orienta, fala, se conselho fosse bom, vendia, é difícil, mas a gente tem que entender que a pessoa tá doente né, então a gente tem que relevar e continuar fazendo a visita normal".

\section{Depoimento da ACS 38}

“(..) ACS nunca deve desistir do paciente, mesmo o paciente não querendo ela. É uma situação de risco, tem que tá investindo nessa visita sim".

\section{Depoimento da ACS 40}

"Eu tinha uma paciente que era bem grossa sabe, na minha frente ela tratava bem, mas quando eu saía ela falava um monte de coisa, só que eu procurei tratar ela profissionalmente e deixei de lado, assim, vou visito ela, vejo como ela tá, vejo a situação dela e ficou por isso, nunca deixei de visitar né, não deixei de acompanhar ela, mas ela é bem grosseira, depende do dia, ela grita de lá pra frente que não quer te atender, passa pra lá porque agora eu não posso".

No segundo caso a resposta foi que ( $n=52,100 \%)$ das ACS não revelariam o caso da paciente portadora de HIV ao marido da mesma.

A Síndrome da Imunodeficiência Adquirida 
(AIDS) trouxe à tona questões éticas imprescindiveis para preservar o ser humano. Vale ressaltar que, inicialmente, adotaram-se Proposta e Diretrizes Éticas Internacionais para a Pesquisa Biomédica envolvendo seres humanos (CIOM/MS, 1982 e 1983), incorporando a Declaração de Helsinque, que foi adotada, em muitos países, inclusive no Brasil, como referencial ético ${ }^{12}$.

Nesse caso, descrevemos os depoimentos da maioria das repostas destacando que as ACS relatam que o sigilo de informações é importante e que o diagnóstico do paciente deve ser relatado pela própria pessoa doente ao seu cônjuge discurso de 11 ACS, ou seja, (21\%).

\section{Depoimento da ACS 1}

"Eu acho que se ela pediu sigilo, eu acho que é ideal a gente manter o sigilo, pelo menor que ela possa. ela queria contar, mas acho que isso não cabe à gente".

\section{Depoimento da ACS 5}

(...) "Eu acho que tem que resolver por outros caminhos, envolver outros profissionais, mas tentar convencer a própria esposa a contar ao marido".

\section{Depoimento da ACS 6}

"A paciente não era casada e não queria que os familiares soubessem, então ela me chamou de cantinho e tudo que ela precisava, agendar TEC, essas coisas, eu trouxe para a minha enfermeira, até que a situação dela agravou, que ela era solteira e morava com a irmã aí foi preciso falar com a família, mas daí ela tomou essa atitude, entendeu? A gente jamais tomou a frente, acho que não se deve, a pessoa que tem que decidir".

A pesquisa mostra que é frequente o contato do ACS com pacientes portadores de HIV e que, para eles, a questão do sigilo é fundamental, embora entendam a importância de ser revelado para proteção do parceiro. Outros estudos evidenciaram o mesmo resultado, inclusive com situações em que o ACS possa vir a ser a primeira pessoa da equipe de saúde a tomar conhecimento do caso, gerando um dilema ético de como deva proceder em relação às dúvidas que possam ser levantadas pelo indivíduo recém-diagnosticado ${ }^{13-14}$.
No caso 3, as ACS já tinham experimentado esta vivência quanto ao acompanhamento de adolescentes. Os adolescentes geralmente apresentam resistência em procurar os serviços de saúde, pois não há assistência hebiátrica específica a eles destinada, além de frequentemente sentirem dificuldade de acesso, especialmente quando não são acompanhados de seus pais ou responsáveis ${ }^{15}$.

Colocamos um ponto importante nesse caso: "A adolescente tem 12 anos". Optamos por dividir a análise dos depoimentos em dois eixos temáticos: Percepção dos ACS no atendimento a adolescentes no item sexualidade e A percepção do ACS quanto à família do adolescente.

Percebemos pelos relatos que as ACS estão preocupadas com o atendimento de adolescentes. Se por um lado procuram respeitar as suas autonomias decisórias, por outro se sentem compromissadas com as orientações na utilização de métodos contraceptivos para que gestações indesejadas sejam evitadas, anseiam transmitir conhecimentos de prevenção de doenças sexualmente transmissiveis e sabem a importância de suas ações no estímulo à realização de consulta com médico e com a enfermeira da UBS e apenas quatro (7\%) depoimentos das ACS serviram de análise para este eixo, os demais depoimentos foram classificados em outros eixos temáticos a serem discutidos brevemente.

\section{Depoimento ACS 3}

(...) "Foi um pouco diferente, porque eu fui orientar a menina poderia tá fazendo o preventivo com a enfermeira".

\section{Depoimento ACS 4}

(...) "Uma menina que teve relação sexual, não com um menino, mas com vários e ela tem treze aninhos, então eu cheguei nela e conversei, mesmo que seu pai ou sua mãe não saiba, você tem que procurar um ginecologista, e me propus até a marcar consulta pra ela".

Com base nas ultimas perguntas sobre código de ética, dois eixos temáticos foram definidos: Eixo Temático a percepção do ACS quanto à existência 
de um código de ética e a percepção do ACS quanto ao respaldo de um código de ética na categoria profissional. A percepção dos ACS pesquisados sobre a existência de um código de ética que os respalde foi unânime, ou seja, todos $(n=52)$ ACS acreditam ou sabem que não existe tal código para a profissão. Descrevemos alguns relatos, porém tivemos pouca complementação nas respostas, ou seja, a maioria se limitou a respostas simples.

\section{Depoimento ACS 2, 7, 9,}

"Não existe".

Depoimentos ACS 10, 15, 18, 28, 32, 34, 36, 38, $43,47,46$,

"Não".

As ACS relataram que o código de ética é uma proteção quanto às normas e regras a serem cumpridas. Relataram que categorias profissionais como médicos, enfermeiros e auxiliares de enfermagem o possuem e quais atribuições são definidas para os mesmos.

Em estudo sobre ACS e ética, esse dado foi muito curioso, visto que a profissão de ACS foi regulamentada em 2002 pela lei 10.507, e ainda não estão vinculados a um conselho de classe profissional. Nesta pesquisa realizada na cidade de Sorocaba - São Paulo, os ACS relataram que todo profissional tem em sua categoria um código de ética, não se atentando que, justamente a sua, não o possui ${ }^{16-17}$.

Em nosso estudo tivemos vários depoimentos semelhantes de ACS que enxergam que a ética permeia seus cotidianos e que a existência de um código seja fundamental e um instrumento de amparo e valorização do trabalho, indicativo dos procedimentos a serem cumpridos de acordo com a ética para o bom nome de sua classe e o melhor para os usuários. Algumas ainda ressaltam que outras categorias têm e que, embora possam ser utilizados como referenciais, não são específicos para orientar suas ações.

\section{Depoimento ACS 2}

"Eu acho muito importante".

\section{Depoimento ACS 5}

"Como todos tem, daí não vejo problema não".

\section{Depoimento ACS 6}

(...) "A gente se baseia no código que tem do auxiliar. os que os profissionais passam pra gente, a gente se baseia nisso".

\section{Depoimento ACS 10}

"Sim com certeza, demais até, a gente lida com muita gente, ai é difícil".

\section{Depoimento ACS 12}

(...) "Seria interessante porque trabalha com muita gente, muitas vidas e realmente são muitos tipos de problemas dificeis".

A ética é considerada um elemento de alto grau no nosso estudo, assim como em outros de mesma natureza ${ }^{18-20}$, nesse sentido a criação de um código de ética a esses profissionais é vital quanto ao amparo de atribuições, responsabilidades, princípios, deveres e direitos, relacionamento com outros profissionais, entre outros. Finalizando, identificamos que o ACS é de fato, um ator importante para a ESF e que situações éticas fazem parte do dia a dia deste profissional. Por meio desse estudo revelamos sentidos que esses agentes estão produzindo na prática de suas ações.

\section{CONCLUSÃO}

Após apresentação desses resultados para a gestão da Secretaria Municipal de Saúde de Rolândia - Paraná, organizou-se um curso de capacitação sobre bioética para os ACS, organizado por alunos e professores do Centro Universitário Filadélfia (UNIFIL) de Londrina - Paraná. Foram utilizadas metodologias ativas, com o preparo de casos problematizadores da prática dos ACS, contextualizando os dilemas éticos e solucionandoos em parceria. Ao final do curso os ACS receberam feedback de suas participações, bem como um certificado e, desta forma, articulou-se ensino e pesquisa, promovendo integração e educação, visando melhorar a eficácia do serviço público por meio de soluções de problemas. 
No que se refere aos ACS do município de Rolândia, percebemos que estes lidam com conflitos éticos e as manifestações pelos participantes desse estudo demonstraram que, apesar de não possuírem um código de ética, em sua maioria, têm uma percepção moralmente correta.

Os aspectos éticos que permeiam circunstâncias comuns da prática diária do ACS foram identificados pelas situações dilemáticas hipotetizadas, que são amplas em sua complexidade, mas propiciaram a análise proposta pelo estudo. Assim, revelou-se estratégia positiva para obtenção dos resultados e poderá ser reproduzida com ACS de outros municípios e estados, corroborando nossos achados no futuro.

Atuar na ESF não requer somente um redirecionamento na prática profissional de um ACS, mas sim do equacionamento ético em um conjunto de situações de seu cotidiano. Temos a expectativa ainda que nosso trabalho possa contribuir para a cristalização deste código, como forma de contribuição e integração dos serviços com o ensino.

\section{REFERÊNCIAS}

1 ROSA WAG, LABATE RC. Programa saúde da família: a construção de um novo modelo de assistência. Rev Latino-am Enfermagem 2005:13(6):1027-34.

2 VASCONCELLOS MPC. Reflexões sobre a saúde da família. In: Mendes, EV, organizador. A organização da saúde no nível local. São Paulo: HUCITEC, 1998. p.155-72.

3 NUNES, MO. Trad LB, Almeida BA de, Homem CR, Melo, MCIC O agente comunitário de Saúde: construção da identidade deste personagem. Cad. saúde pública 2002,18(6):1639-46.

4 FORTES PAC, SPINETTI SR. O agente comunitário de saúde e a privacidade das informações dos usuários. Cad Saúde Pública 2004:20(5):1328-33

5 Garbin AJI, Garbin CAS, Moimaz SAS; Diniz DG. Ética e atuação profissional: percepção de Agentes Comunitários de Saúde. Saúd Étic \& Just 2011;00(2):65-71

6 ABRACOM. Código de Ética [Internet]. São Paulo: Abracom: [citado 2018 Out 20].13 p. Disponivel em: http://www.abracom. org.br/down/codigo_etica.pdf]. Acesso em: 20/10/2018.

7 Zoboli ELCP. Fortes PAC. Bioética e atenção básica: um perfil dos problemas éticos vividos por enfermeiros e médicos do Programa Saúde da Família. Cad Saúde Pública 2004:20(6):1690-99.
8 Schwengber C. Aspectos históricos de Rolândia. Rolândia: Wa Ricieri- Gráfica; 2003. p. 33-47.

9 Brasil. Ministério da Saúde. Portaria GM/MS nº 1.886 de 18 de dezembro de 1997. Normas e Diretrizes do Programa dos Agentes Comunitários e Programa de Saúde da Família. Diário Oficial da União, Poder Executivo, Brasilia, DF,18 nov. 1997.

10 Bardin L. Análise de conteúdo. Lisboa, Portugal: Edições 70 2009.

11 Smeltzer SC, Bare BG. Histórico e tratamento de pacientes com hipertensão. In: Tratado de Enfermagem Médico Cirúrgica. 9. ed. Rio de Janeiro: Guanabara Koogan; 2002. p.690-700.

12 Oselka G. Bioética clínica: reflexões e discussões sobre casos selecionados. São Paulo: Conselho Regional de Medicina do Estado de São Paulo, Centro de Bioética; 2008. 266 p.

13 Seoane A, Fortes PAC. A percepção do usuário do Programa Saúde da Família sobre a privacidade e a confidencialidade de suas informações. Saúde Soc 2009:18(1):42-9.

14 Seffner F. O conceito de vulnerabilidade: uma ferramenta úti em seu consultório [Internet]. Canoas: UNILASALLE; 2005 [citado 2018 Out 20]. Disponivel em: [http:/www.unilasalle.edu.br/seffner/ artigo4.htm].

15 Carvacho IE et al. Fatores associados à gestação a serviços de saúde por adolescentes gestantes. Rev Saúde Pública 2008:42(5):886-94

16 Mendonça MHM de. Agente comunitário de saúde: o ser, o saber, o fazer. Cad Saúde Públ 2004;20( 5 ):1433-34.

17- BRASIL, Secretaria de Atenção à Saúde, Departamento de Atenção Básica. Vigilância em saúde. 2. ed. Brasília: Ministério da Saúde; 2008. 200 p.

18 Vidal SM, Souza Motta LC, Siqueira-Batista R. Agentes comunitários de saúde: aspectos bioéticos e legais do trabalho vivo. Saúde Soc São Paulo 2015:24(1):129-40.

19 Garbin AJI, Garbin CAS, Moimaz SAS, Diniz DG. Ética e atuação profissional: percepção de Agentes Comunitários de Saúde. Saúde, Ética \& Justiça 2011;00(2):65-71.

20 Gomes AP, Gonçalves LL, Souza CR, Siqueira-Batista R. Estratégia Saúde da Família e bioética: grupos focais sobre trabalho e formação. Revista Bioética 2016:24(3):488-494. 